Please send trade news information and illustrations to Arveen Bajaj at the $B D J$, Nature Publishing Group, The Macmillan Building, 4-6 Crinan Street, London N1 9XW.

Trade news is provided as a service to readers using text and images from the manufacturer, supplier or distributor and does not imply endorsement by the $B D J$. Normal and prudent research should be exercised before purchase or use of any product mentioned.

\section{Website provides spring clean for staff}

A new website that provides clinical staff (including dental and primary care) with guidance on the effective decontamination of surgical instruments has been launched by specialist washing company Dawmed International. The site, www.dawmed-clinic.co.uk provides a wide range of news and information, covering key topics such as regulatory information, best practice, frequently asked questions and an innovative cost/feature comparisons' tool to determine potential cost savings when moving from manual washing to an automated process.

Within the website users can also see Dawmed's own solutions for the washing, disinfecting and drying of surgical instruments in the clinical environment, one of which is the new Dawmed clinic, a purpose designed compact washer disinfector dryer for applications where speed is essential and space is at a premium. Reader response number $\mathbf{5 1}$

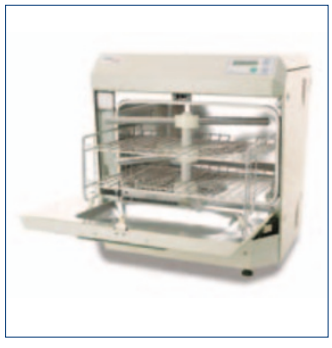

\section{New washable mouse}

A computer mouse that can be completely sterilised simply by washing in antibacterial or sterilising fluid has been launched by Unotron Limited. It is hoped that the ScrollSeal washable mouse may help to combat MRSA within clinical environments. The washable mouse complements the company's SpillSeal keyboard which uses patented technology to individually seal each key, therefore protecting the internal parts of the keyboard from liquid and dust while retaining the touch type feel of a top quality PC keyboard.

The affordable SpillSeal Keyboards have widespread applications not only for dental clinics but also general hospital wards and clinics and other institutions such as schools, offices and libraries. For more information visit www.unotrononline.co.uk.

\section{TRADE NEWS \\ WHAT'S NEW}

\section{Longer life rotary instrument}

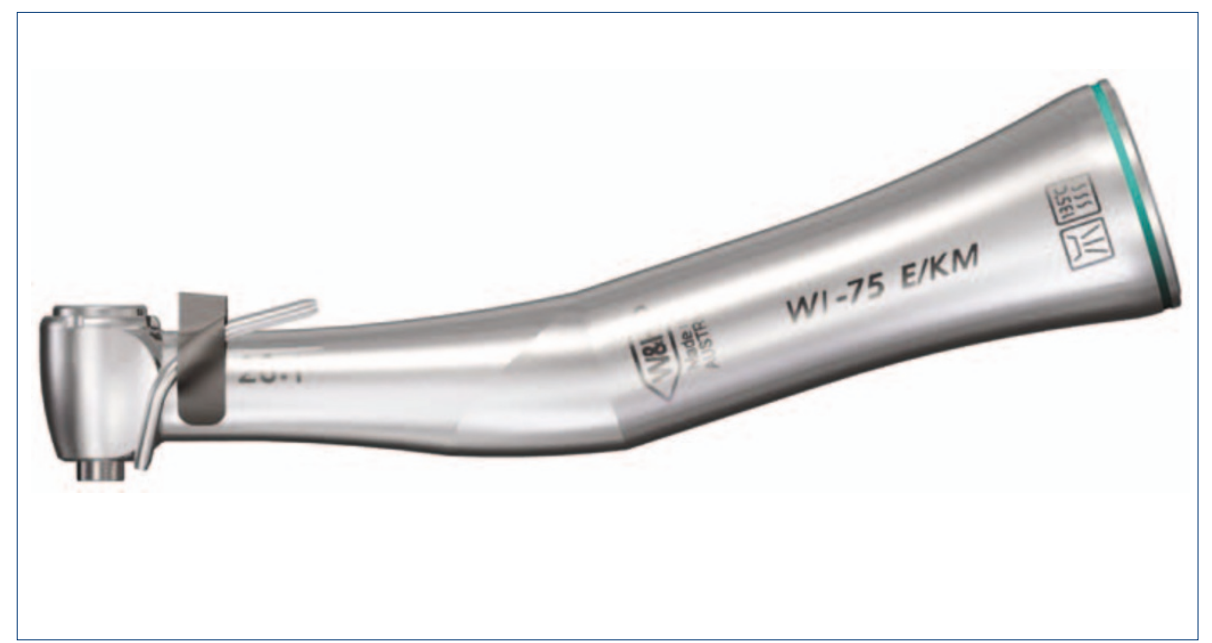

Astra Tech has developed a new implantology handpiece. The WI-75 E/KM is a precision instrument in compliance with all current standards and directives.

The product is $100 \%$ stainless steel, has a small head shape and slim profile, features a removable spray clip and internal bur cooling and is simple to clean.

The handpiece has an innovative hexagon chucking system that ensures application safety at high torques and can prevent jamming or deformations of the rotary instruments at torques above $30 \mathrm{Ncm}$. Existing burs and rotary instruments can continue to be used with this future-proof solution that provides longer life of rotary instruments and a contra-angle handpiece.

Reader response number 50

\section{Dental spell checker}

The Spellex Corporation has launched a new 2006 version of its premium dental spelling software for Microsoft and other programs. The new release includes more than 415,000 specialty words from the dental, medical, and pharmaceutical sectors in the United Kingdom.

The spelling dictionaries allow users to more quickly and accurately create professional looking documents. By adding Spellex Premium Dental to a common UK English language spell checker, the spell checkers will verify correctly spelt dental and pharmaceutical words and provide correct spelling choices for incorrectly spelt terms. They also allow users to verify unsure spelling of dental terminology by phonetic or typographical search as they type.

It covers terms from all areas of general and hospital dentistry, including preventive dentistry, oral diagnosis, temporomandibular disorders, and restorative, aesthetic, and implant dentistry. Spellex Dental includes subspecialties of dental medicine covering oral pathology, radiography, orthodontics, endodontics, prosthodontics, paedodontics, periodontics, and dental pharmacology plus related drugs, equipment, and materials.

Spellex correctly spells thousands of OTC drugs and prescription pharmaceuticals, generic and trade name drugs, orphan drugs, pharmaceutical manufacturers, and drug distributors. The pharmaceutical speller includes comprehensive pharmacologic - therapeutic classifications covering anaesthetics, anti-infective agents, central nervous system agents, dental agents, diagnostic agents, vaccines, vitamins, and more.

Reader response number 53

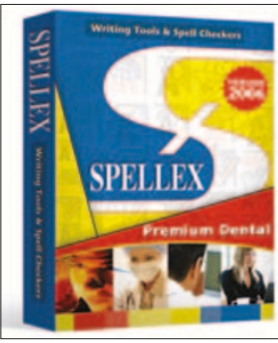



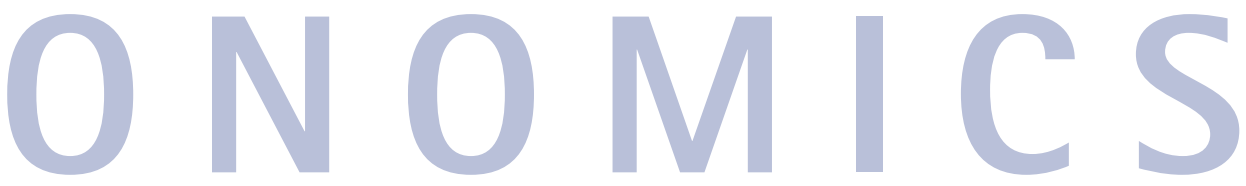

\section{Improve your posture}

Cutting edge ergonomics

The DynamoSeat and InCharge stools from Evident are ergonomically designed to automatically correct your seating position, improving posture and encouraging active stimulation of blood circulation no matter what height you are working at.

Manufactured in Denmark, full mobility around the surgery is assured by the stool's soft castors which are suitable for all types of floor surface. Washable, fabric seat covers ensure cleanliness and hygiene and they also have easy to replace covers. Reader response number 54
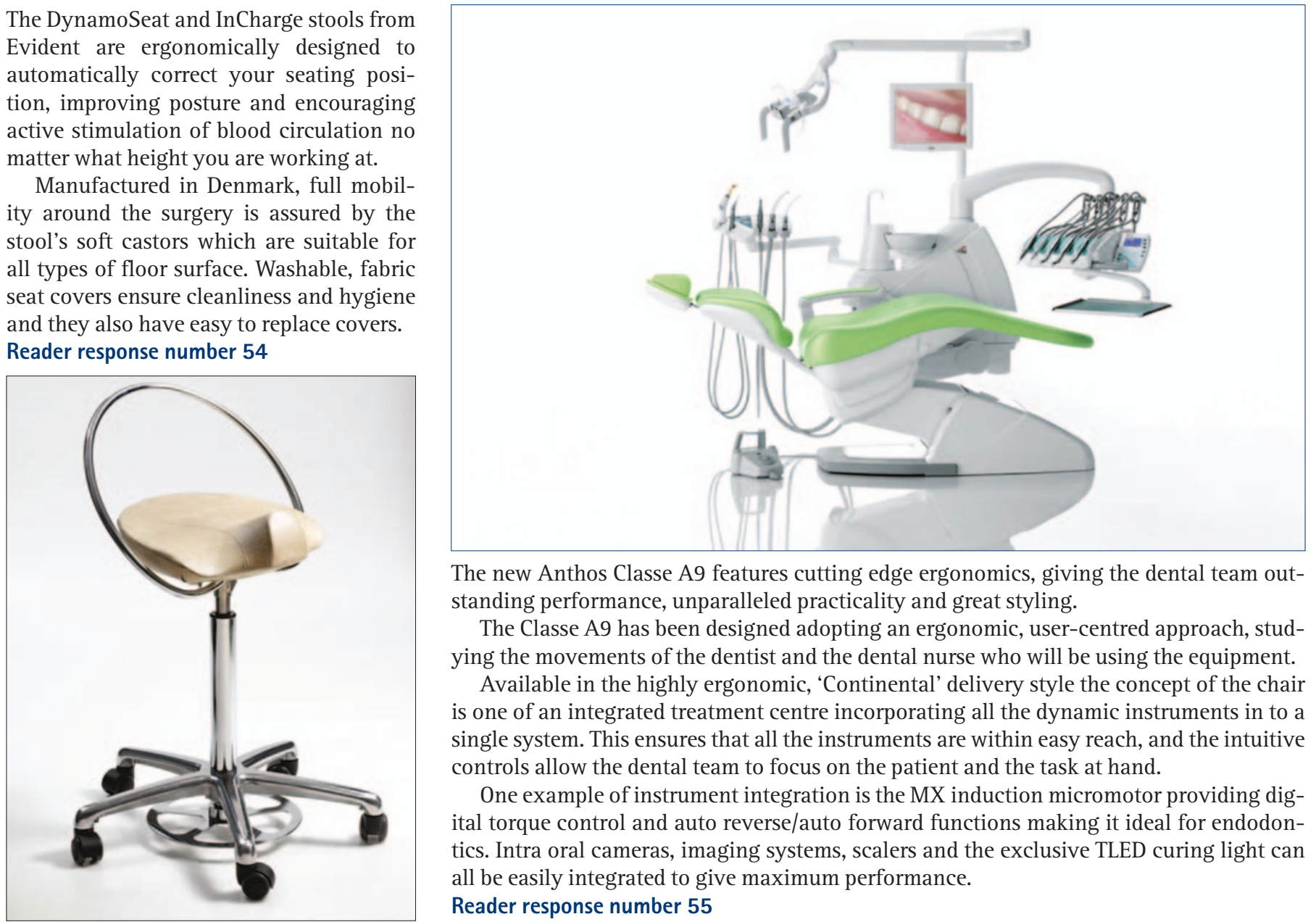

The new Anthos Classe A9 features cutting edge ergonomics, giving the dental team outstanding performance, unparalleled practicality and great styling.

The Classe A9 has been designed adopting an ergonomic, user-centred approach, studying the movements of the dentist and the dental nurse who will be using the equipment.

Available in the highly ergonomic, 'Continental' delivery style the concept of the chair is one of an integrated treatment centre incorporating all the dynamic instruments in to a single system. This ensures that all the instruments are within easy reach, and the intuitive controls allow the dental team to focus on the patient and the task at hand.

One example of instrument integration is the MX induction micromotor providing digital torque control and auto reverse/auto forward functions making it ideal for endodontics. Intra oral cameras, imaging systems, scalers and the exclusive TLED curing light can all be easily integrated to give maximum performance.

Reader response number 55

\section{Intelligent drive unit}

The new Implant Drilling Unit from Astra Tech has been designed specifically for implantology with an intelligent drive unit for dental surgical applications that is simple to use with sophisticated software, a powerful motor and an integrated coolant pump.

The reliable, easily maintained, ergonomic design of the product ensures maximum efficiency, safety and ease of use. The smooth, stylish shape is easy to keep clean with a large display screen that is ideal for ease of viewing. The new maintenance free Implant Unit's premium performance brushless motor is short and correspondingly light with a wide speed range of 300 - 40,000 rpm, so it runs quietly and the motor holder can be neatly secured to the stand.

Bright programme switches on the Implant Unit foot control are ideal for identifying the programmes with ease. The foot control also boasts on and off switching of the coolant pump, clockwise/anticlockwise running, on/off function and smoothly variable motor control up to the preselected maximum speed. Every Astra Implant Drilling Unit comes complete with console, motor, motor holder, foot control, stand, set of spray tubing, clip set for tubing and sterilisation cap.

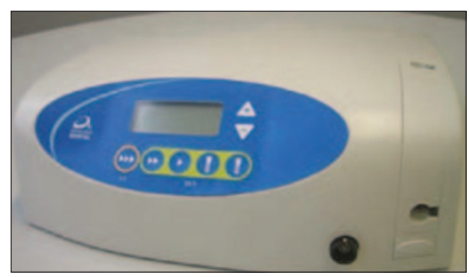




\section{Gloves in a hurry}

The Express Glove department at Kent Express produces regular offers with competitive prices and free gifts on selected glove ranges. The most recent promotion, available until 31 August offers, 'Buy 1 case get 1 free' on any Cybertech branded gloves including their Aloe Vera coated gloves that keep your hands moisturised throughout the day.

Alternatively, you can try Kimberly Clark's new nitrile Sterling Gloves and receive a free Sony digital camera when you buy seven cases. These gloves offer value for money with 50\% more gloves than other competitive products as well as using natural rubber latex-free material, ideal for those with latex sensitivity. They also boast an excellent fit and feel compared to latex, with excellent tactile sensitivity and durable barrier.

All glove requirements are met when you buy from the Express Glove Department, with a vast array of branded and non-branded ranges available.

Reader response number 57

\section{Stainless steel dental cabinetry}

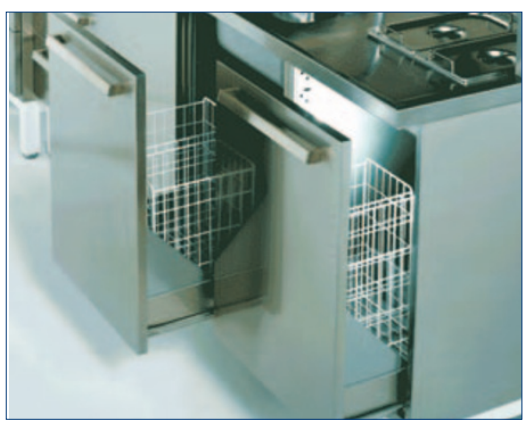

Tavom provide a range of stainless steel dental cabinetry with exceptional corrosion resistance and easily cleaned surfaces for efficient hygiene and infection control. The sleek, steel surfaces are visually attractive, easy to decontaminate and keep sterile, and ideal for radionuclide work. The stainless steel employed is molybdenum charged, while susceptible to fluidic and chromic acids and abrasion, is resistant to most other acids and base corrosion.

Reader response number 58

\section{Better back care}

The riding-style body position on a Salli Saddle Chair can help prevent many sitting disorders including low back pain, neck and shoulder tensions, and joint problems in the knees and hips according to its manufacturer. The chair enables the dental practitioner to lean forward and turn, without stretching the back or the neck into unsafe positions. Development of the Salli Saddle Chair began due to the lack of a comfortable and back friendly chair on the market. In cooperation with experts on back physiology, the company applied the latest knowledge in ergonomics to create a physiologically optimal chair for demanding long term work. The basic idea for improved ergonomics is to change traditional sitting into a riding type of sitting position. Reader response number 59

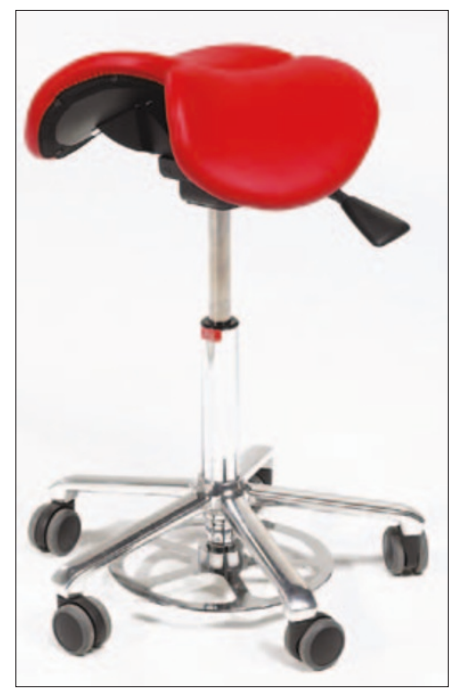

\section{Comfortable loupes}

Evident's range of orascoptic loupes are manufactured to the highest standards of quality and supported by a team of highly trained consultants, who are able to advise on the most suitable type of magnification for you. Evident's consultants will visit your practice on request and take the precise measurements necessary to manufacture your personalised, custom-made through-the-lens loupes.

Orascoptic loupes are renowned for their product quality, with lightweight coated high index lenses, which maximise light transmission. This provides the brightest

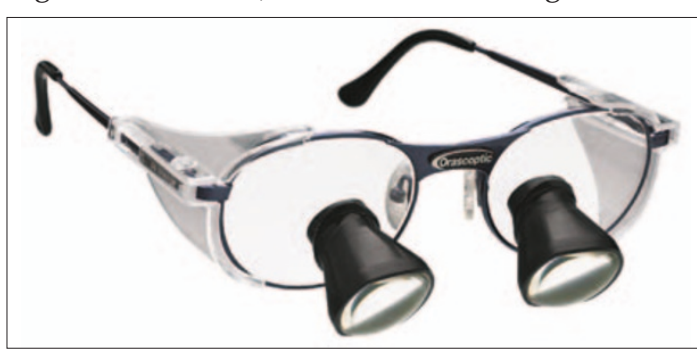

possible image combined with enhanced width and depth of field.

The company claims that finding the right magnification is extremely important and qualities such as function and comfort are foremost.

Reader response number 60

\section{Options to suit all}

Henry Schein's cabinetry range offers silver, gold and platinum options to suit every practice's needs. Premier Cabinets, which have been manufactured in Sedburgh, Cumbria since 1910, are synonymous with outstanding workmanship, longevity and customer satisfaction, while the Premier Base Line dental cabinets are entry level units representing unbeatable value for money. They however deliver the quality normally associated with top of the range products.

Premier High Line cabinetry offers dentists unbeatable high quality craftsmanship, attention to detail and a wide choice of options which allows every surgery to be as individual as its owner.

If only the very best will do, Henry Schein offers the top of the range Baisch Cabinetry where options are unlimited.

Reader response number 61

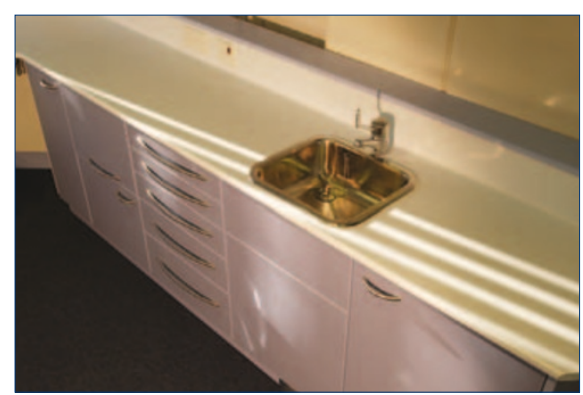

\section{Added bounce}

Although saddle seats have been around for a number of years they tend to be used by business professionals such as dentists and musicians rather than for general back care. The Bambach saddle seat swivel base houses the central height adjustment gas piston which, when locked, allows a small amount of 'bounce' for added comfort. The base is fitted with easy-glide castors which allow you to 'scoot' around your workplace with total ease.

The instructions are well written and describe the correct way to sit on the saddle. The upper thighs should be at $45^{\circ}$ to the top of the body and feet resting on the floor so that you adopt the correct horse riding straddle. The saddle is very comfortable and has a curved rear lip which is higher than on standard horse saddles or other saddle seats. This feature tends to encourage a forward pelvic tilt which keeps the spine straight, encouraging the natural lumbar curve and discourages sitting in the forward slump, on one buttock or fidgeting from side to side.

According to Bambach, people with a posteriorly rotated pelvis who habitually slump in the classic ' $\mathrm{C}$ ' would definitely benefit from this particular design feature.

Reader response number 62 